\title{
Memahami Hadis-hadis Keutamaan Menghafal al-Qur'an dan Kaitannya dengan Program Hafiz Indonesia di RCTI (Aplikasi Hermeneutika Nasr Hamid Abu Zaid)
}

\author{
Ulummudin \\ UIN Sunan Kalijaga Yogyakarta \\ Ulummudin53@gmail.com
}

DOI: $10.29240 /$ alquds.v4i1.1103

Submitted: 2019-09-28 | Revised: 2020-03-19| Accepted: 2020-04-15

\begin{abstract}
This paper aims to understand hadiths related to the benefit of memorizing the Qur'an in the contemporary era. The review is needed because now memorizing the Qur'an has been a trend and even exploited for the sake of commercial interest such as Hafiz Indonesia program in RCTI. The method which is used to explain the meanings of hadiths is Nasr Hamid Abu Zaid's hermeneutic. The hermeneutic is trying to peel three levels of intended meaning. They are dalalat (meaning), maghza (significance), and maskut anbu (unspoken things). Based on the application of the hermeneutic, the result is that the meaning of the hadith is a form of motivation which was delivered by the prophet, so that the companions were enthusiastic for memorizing the Qur'an. The purpose is that the Qur'an had to be maintained for the next generations. The manner of keeping the Qur'an, according to that time tradition was by memorizing it. Meanwhile, the significance is practicing the teachings of the Qur'an in daily life. The Qur'an is not enough to only exist in their memories, but also it must be applied in their behavior. To get virtue and honor in the world and after life, individual piety (memorizing the Qur'an) must be parallel with social piety (interaction with the others). The last, its maskut anbu is a prohibition of memorizing the Qur'an for popularity and economic interest.
\end{abstract}

Keywords: Hermeneutic; Nasr Hamid Abu Zaid; Hadith; memorizing the Qur'an

Abstrak. Tulisan ini bertujuan untuk memahami hadis-hadis terkait dengan keutamaankeutamaan menghafalkan al-Qur'an ditinjau dalam konteks kontemporer. Pengkajian ulang diperlukan karena saat ini menghafal al-Qur'an sudah menjadi trend dan bahkan, dieksploitasi untuk kepentingan komersial seperti program Hafiz Indonesia di RCTI. Metode yang digunakan untuk menjelaskan maksud hadis-hadis adalah hermeneutika Nasr Hamid Abu Zaid. Hermeneutika ini berusaha untuk mengungkap dua level pemaknaan yakni dalalat (makna) yang bersifat statis, maghza (signifikansi) yang bersifat dinamis, danmaskut anbu (hal yang tak terkatakan) yang menjadi pesan inti teks. Berdasarkan penerapaan hermeneutika tersebut dihasilkan bahwa makna dari hadishadis tersebut adalah sebuah motivasi yang diberikan nabi agar para sahabat bergairah 
dalam menghafal al-Qur'an. Tujuannya, supaya al-Qur'an tetap terjaga dan dapat diajarkan kepada generasi selanjutnya. Cara menjaganya adalah melalui hafalan sesuai dengan tradisi saat itu. Sementara, signifikansinya adalah mengamalkan ajaran-ajaran yang terkandung dalam al-Qur'an pada kehidupan.Al-Qur'an tidak cukup hanya hadir dalam memorinya, tetapi juga dalam tingkah lakunya. Untuk mendapatkan keutamaan di dunia dan akhirat, kesalehan individu (menghafal al-Qur'an) harus sejalan dengan kesalehan sosial (interaksi dengan orang lain). Kemudian, maskut anbunya adalah larangan menghafal al-Qur'an dengan motif kepentingan ekonomi dan popularitas.

Kata kunci: Hermeneutika; Nasr Hamid Abu Zaid; Hadis; Menghafal al-Qur'an.

\section{Pendahuluan}

Hadis-hadis yang berbicara tentang keutamaan-keutamaan menghafalkan al-Qur'an telah memberikan inspirasi dan motivasi kepada sebagian umat Muslim Indonesia untuk menghafal al-Qur'an. Karena hadis tersebut, menghafal al-Qur'an kini menjadi sebuah trend di Indonesia. Banyak dari kalangan anakanak maupun dewasa yang menggandrunginya. Mereka tergiur dengan kedudukan yang akan diperoleh di akhirat jika mereka hafal al-Qur'an. Namun, apakah hafal al-Qur'an saja sudah cukup untuk menjadi jaminan meraih surga. Untuk menemukan menjawabnya, hadis-hadis tersebut perlu dijelaskan secara komprehensif dan mendalam.

Kaitannya dengan teks keagamaan, hadis menempati kedudukan utama setelah al-Qur'an. Ia menjadi teks sekunder yang memberi komentar atau menjelaskan teks primer yakni al-Qur'an. ${ }^{1}$ Kehadiran sebuah teks keagamaan mempunyai implikasi yang besar terhadap perkembangan intelektual, kebudayaan, dan peradaban. ${ }^{2}$ Ia menjadi sumber rujukan yang terpercaya bagi pengikut-pengikutnya.

Salah satu bukti konkret dari pengaruh sebuah teks dalam hal ini hadis terhadap kebudayaan adalah menjamurnya rumah dan pondok-pondok tahfidz saat ini. Tak cukup di situ, trend ini dimanfaatkan oleh para pebisnis yang berkecimpung dalam dunia hiburan. Oleh mereka, ritual menghafal al-Qur'an diseret ke ranah komersial yang berujung pada keuntungan materi sebagai tujuannya. Al-Qur'an yang sakral menjadi tontonan dengan segala aksi yang mengikutinya.

Salah satu acara yang rutin ditayangkan adalah Hafir. Indonesia, perlombaan menghafal al-Qur'an yang diadakan setiap bulan Ramadhan di

${ }^{1}$ Lailatur Rohmah, "Hermeneutika Al-Qur'an: Studi Atas Metode Penafsiran Nasr Hamid Abu Zaid," Hikmah Journal of Islamic Studies 12, no. 2 (2016): 223-44.

${ }^{2}$ Nur Ahmad, "Kajian Hermeneutik Al-Qur'an Kontemporer: Telaah Kritis Terhadap Model Hermeneutika Nasr Hamid Abu Zaid," HERMENEUTIK 9, no. 1 (2015): 115-38, doi:10.1234/hermeneutik.v9i1.886. 
RCTI. Program ini sudah berlangsung dari tahun 2013 sampai sekarang. Yang menjadi peserta biasanya dari kalangan anak-anak yang masih polos. ${ }^{3}$ Selama pertunjukan, bagian hafalannya hanya berdurasi beberapa menit. Namun, sisanya hanya menampilkan drama yang seolah digiring untuk menarik simpati dan empati penonton. Dengan demikian, penonton akan terbius dengan segala hal yang ditampilkan, sehingga rating TV acara tersebut menjadi naik. Jika hal ini terjadi, maka maksud sebenarnya tercapai yakni keuntungan ekonomi bagi pihak yang terlibat.

Fenomena tersebut digerakkan oleh hadis yang menjadi teks rujukan dalam setiap amalan umat Muslim. Hal tersebut juga mengindikasikan adanya pergeseran ekspresi pengamalan hadis keutamaan menghafal al-Qur'an di setiap zaman. Hingga sampai pada kondisi saat ini dimana menghafal al-Qur'an sudah dianggap sebagai trend yang menyimbolkan kesalehan individu dan jaminan kebahagiaan di akhirat. Trend ini mungkin saja berbeda dengan tujuan awal disabdakannya hadis tersebut oleh Nabi kepada para sahabatnya. Oleh karena itu, hadis-hadis terkait keutamaan bagi penghafal al-Qur'an harus ditinjau kembali untuk mencari maksud sesungguhnya dari sabda-sabda Nabi tersebut.

Fakta yang demikian adalah bukti bahwa hadis memainkan peranan penting dalam kebudayaan dan peradaban. Maka selanjutnya, hal yang tak kalah urgent adalah menentukan metode yang tepat untuk memahami hadis tersebut. ${ }^{4}$ Untuk menemukan makna yang dimaksud, pada tulisan ini diterapkan metode hermeneutika yang ditawarkan oleh Nasr Hamid Abu Zayd. Hermeneutikanya berusaha untuk menemukan dalalah atau makna yang bersifat historis, signifikansi sebagai pemaknaan kontekstualnya, ${ }^{5}$ dan maskut anbu untuk menangkap makna implisitnya. ${ }^{6}$

Sementara itu, penerapan metode penafsiran Nasr Hamid Abu Zayd selama ini lazim digunakan untuk menafsirkan al-Qur'an. Namun, bukan tidak mungkin diaplikasikan untuk kajian hadis karena keduanya termasuk ke dalam teks linguistik dan historis. Sejauh penelusuran penulis, tulisan yang menggunakan metode Nasr Hamid untuk menjelaskan hadis adalah tulisan yang

3"Hafiz Indonesia," in Wikipedia bahasa Indonesia, ensiklopedia bebas, February 20, 2020, https://id.wikipedia.org/w/index.php?title=Hafiz_Indonesia\&oldid=16576004. diakses pada tanggal 11 April 2020.

${ }^{4}$ Ahmad, "Kajian Hermeneutik Al-Qur'an Kontemporer," 128.

${ }^{5}$ Rohmah, “Hermeneutika Al-Qur'an,” 236.

${ }^{6}$ Mohamad Nuryansah, "Aplikasi Hermeneutika Nashr Hāmid Abū Zaid Terhadap Hadis Nabi (Studi Pada Hadis Perintah Memerangi Manusia Sampai mereka Mengucapkan tiada tuhan selain Allah')," Millati: Journal of Islamic Studies and Humanities 1, no. 2 (2016): 259-78, doi:10.18326/mlt.v1i2.259-278. 
berjudul Aplikasi Hermeneutika Nashr Hamid Abu Zaid terbadap Hadis Nabi (Studi pada hadis "Perintah Memerangi Manusia sampai Mereka Mengucapkan Tiada Tuban Selain Allab). ${ }^{\top}$ Adapun pembahasan terkait fenomena hafiz Qur'an yang telah dilakukan sebelumnya adalah tulisan dengan judul Pengarub Intensitas Menonton Program Acara Hafiz Indonesia di RCTI terbadap Motivasi Membaca Al-Qur'an Remaja di Desa Pasir Kecamatan Mijen Kabupaten Demak. ${ }^{8}$ Dengan demikian, kajian terhadap hadis keutamaan menghafal al-Qur'an dengan metode hermeneutika Nasr Hamid belum pernah dibahas.

\section{Latar Sosio Historis Nasr Hamid Abu Zaid}

Nasr Hamid Abu Zaid lahir pada 10 Juni 1943 di desa Quhafa, kota Thantha, Mesir. Kecerdasannya sangat menonjol dari sejak kecil. Umur 8 tahun, Nasr sudah hafal al-Qur'an. Ia juga lahir di keluarga pengikut Ikhwan alMuslimun, sehingga di umur yang masih belia -11 tahun- dia masuk kelompok ini. Bahkan, ia pernah dipenjara karena namanya ada dalam daftar anggota tersebut. Namun, ia akhirnya dibebaskan karena masih di bawah umur.9

Nasr menyelesaikan pendidikan dasar dan menengahnya di kota kelahirannya, Thantha. Kemudian, ia melanjutkan ke sekolah teknik Thantha sampai lulus pada tahun 1960. Setelah lulus, ia bekerja sebagai teknisi elektronik pada Organisasi Komunikasi Nasional di Kairo sampai tahun 1972. Di sela-sela bekerja, tahun 1968, ia juga meneruskan pendidikan di jurusan Bahasa dan Sastra Arab, Fakultas Sastra, Universitas Kairo. Setelah lulus, ia diangkat menjadi asisten dosen. Saat itu, ada kebijakan bahwa asisten dosen wajib mengambil studi Islam pada jenjang Master dan Doktor. Sejak itu, Nasr yang memiliki basic sastra harus bergelut dengan kajian keislaman. Pendidikan Masternya ditempuh pada tahun 1975 di Universitas Amerika yang berlokasi di Kairo dengan beasiswa Ford Foundation. Tak lama berselang, dalam rentang 1976-1978, Nasr menjadi pengajar bahasa Arab bagi orang-orang Asing di pusat diplomat dan di Kementrian Pendidikan.10

Pada tahun 1978, Nasr sempat menjadi fellow di Center for Middle East Studies di Universitas Pensylvania, Philadelphia, Amerika. Pada kesempatan itu, ia mempelajari ilmu-ilmu sosial dan humaniora, khususnya teori-teori tentang

\footnotetext{
${ }^{7}$ Ibid.

${ }^{8}$ Fatkhiatus Sa'adah, "Pengaruh Intensitas Menonton Program Acara Hafiz Indonesia
} Di RCTI Terhadap Motivasi Membaca Al-Qur'an Remaja Di Desa Pasir Kecamatan Mijen Kabupaten Demak" (Skripsi, Fakultas Dakwah dan Komunikasi UIN Walisongo Semarang, 2018).

${ }^{9}$ Moch. Nur Ichwan, Meretas Kesarjanaan Kritis Al-Qur'an: Teori Hermeneutika Nasr Abu Zayd (Jakarta: Teraju, 2003), 15-16.

${ }^{10}$ Ali Imron, "Hermeneutika Al-Qur'an Nasr Hamid Abu Zayd," in Hermeneutika AlQur'an Dan Hadis, ed. Sahiron Syamsuddin (Yogyakarta: eLSAQ Press, 2010), 116-17. 
cerita rakyat. Pada periode ini juga untuk pertama kalinya, ia berhubungan dengan hermeneutika Barat. Tak puas dengan karir akademiknya, ia melanjutkan studi Doktor di universitas Amerika di Kairo dengan jurusan yang sama yakni studi Islam. Ia berhasil lulus dengan predikat cum laude. Ia juga sempat menjadi seorang professor tamu di Universitas Osaka, Jepang tahun 1985-1989.11

Ketika usianya menginjak 49 tahun, pada bulan April 1992, Nasr menikah dengan Dr. Ibtihal Ahmad Kamal Yunis. Ia seorang professor bahasa Prancis dan sastra perbandingan di Universitas Kairo. Namun, di tahun yang sama, ketika Nasr mengajukan untuk menjadi professor, ia dituduh telah merusak ortodoksi Islam. Bahkan, tahun 1995 Pengadilan Kairo menyatakan bahwa ia telah keluar dari Islam, sehingga pengadilan menuntut agar Nasr dan Isterinya bercerai. Dalam posisi terdesak seperti itu, akhirnya Nasr memutuskan berhijrah bersama isterinya ke negeri Belanda untuk menjadi professor tamu di Universitas Leiden dalam bidang studi Islam. Sebelum pergi ke Leiden, pada tahun yang sama ia telah memperoleh gelar professor setelah menyerahkan Sembilan karyanya kepada panitia promosi. 12

Selama berkarir dalam dunia akademis, Nasr telah banyak melahirkan karya-karya ilmiah. Karya pertamanya adalah Hawl Adab al-'Ummal wa alFallahin (Tentang Sastra Buruh dan Petani) dan Azmah al-Aghniyyah alMishriyyah (Krisisi Lagu Mesir) yang diterbitkan di jurnal al-Adab pimpinan Amin al-Khuli. Ia juga menulis tesis yang berjudul al-Ittijah al-'Aqli fi al-Tafsir: Dirasah fi Qadhiyyat al-Majaz fi al-Qur'an 'inda al-Mu'tazilah (Rasionalisme dalam Tafsir: Sebuah Studi tentang Problem Metafor menurut Mu'tazilah) dan disertasi Falsafat al-Ta'wil: Dirasat fi Ta'wil al-Qur'an 'inda Muhy al-Din ibnu 'Arabi (Filsafat Takwil: Studi Hermeneutika al-Qur'an Muhy al-Din ibnu 'Arabi). Karyanya yang lain adalah Mafhum al-Nash: Dirasah fi al-'Ulum al-Qur'an (Konsep Teks: Studi tentang Ilmu-ilmu al-Qur'an) yang ditulisnya ketika di Jepang. Dua karya yang diajukan untuk menjadi professor adalah Naqd alKhittab al-Dini (Kritik Wacana Agama) dan al-Imam al-Syafi'i wa Ta'sis alAidiyulijiza al-W asathiyyah (Imam Syafi'i dan Pendirian Ideologi Moderat). ${ }^{13}$

\section{Hermeneutika Nasr Hamid Abu Zaid}

Hermeneutika yang dikembangkan oleh Nasr Hamid awalnya digunakan untuk menafsirkan al-Qur'an. Namun, tidak menutup kemungkinan metodenya untuk dipakai pada teks-teks lain seperti hadis. Nasr mempunyai dua tujuan

11 Fikri Hamdani, "Teori Interpretasi Nasr Hamid Abu Zayd," Farabi: Journal of Ushuluddin \& Islamic Thought 13, no. 1 (2016): 30-45.

${ }^{12}$ Nur Ichwan, Meretas Kesarjanaan Kritis Al-Qur'an, 22.

${ }^{13}$ Ahmad, "Kajian Hermeneutik Al-Qur'an Kontemporer," 120. 
dalam melakukan studi teks (al-Qur'an). Pertama, untuk mengaitkan kembali studi al-Qur'an dengan studi sastra dan studi kritis. Menurutnya, studi Islam dan al-Qur'an harus didasarkan atas teks. Studi al-Qur'an sebagai sebuah teks linguistik meniscayakan penggunaan studi linguistik dan sastra. Untuk melakukan ini, Nasr mengadopsi teori-teori mutakhir dalam bidang linguistik, semiotik, dan hermeneutika dalam kajian-kajian tentang al-Qur'an. Kedua, untuk mendefinisikan pemahaman objektif tentang Islam yang terhindar dari kepentingan-kepentingan ideologis. Nasr menyadari bahwa ada kelompokkelompok yang menggunakan Islam secara ideologis untuk mendukung tujuantujuan politik dan ekonomi. ${ }^{14}$

Nasr mendudukan konsep teks sebagai pusat dalam riset akademik Islam dengan menolak teori tradisional tentang al-Qur'an dan hadis sebagai sebuah teks tertutup. Sebaliknya, ia menjadikan al-Qur'an dan hadis sebagai teks terbuka dan meniscayakan interpretasi sebagai kunci untuk membuka dunia teks. Ia berusaha untuk merekonstruksi sebuah teori hermeneutika al-Qur'an dan hadis berdasarkan pendekatan linguistik dan sastra. ${ }^{15}$

Diskursus penting dalam hermeneutika Abu Zayd adalah konsep mengenai teks. Ia memandang bahwa teks yang bersumber dari ilahi telah "termanusiakan" semenjak ia mewujud dalam sejarah dan bahasa. ${ }^{16}$ Ketika teks diwahyukan kepada Nabi, ia telah bertransformasi dari teks ilahi kepada teks manusiawi. Al-Qur'an dan hadis diturunkan tidak dalam ruang hampa, tetapi hadir dalam sebuah realitas.

Dari realitas terbentuklah teks dan dari bahasa dan budaya terbentuklah konsepsi-konsepsi. Pandangan ini membawa kepada kesimpulan bahwa alQur'an adalah "produk budaya". Maksudnya, teks muncul dalam sebuah struktur budaya abad ketujuh selama lebih dari dua puluh tahun dan ditulis berpijak pada aturan-aturan budaya tersebut, yang menggunakan media bahasa untuk menyampaikan maksudnya. Pada akhirnya, teks melahirkan sebuah budaya baru sesuai dengan pandangan dunianya saat itu. ${ }^{17}$

Jadi, yang dimaksud dengan al-Qur'an sebagai produk budaya adalah menyadari bahwa al-Qur'an diturunkan dalam realitas dan budaya tertentu. Abu Zaid sama sekali tidak menghilangkan sisi kesakralan al-Qur'an. Ia tetap mengakui al-Qur'an sebagai teks yang dikarang oleh Allah. Ia hanya merubah

${ }^{14}$ Moch. Nur Ichwan, "Al-Qur'an Sebagai Teks (Teori Teks Dalam Hermeneutik Qur'an Nasr Hamid Abu Zayd," in Studi Al-Qur'an Kontemporer: Wacana Baru Berbagai Metodologi Tafsir, ed. Abdul Mustaqim and Sahiron Syamsuddin (Yogyakarta: Tiara Wacana, 2002), 152-53.

${ }^{15}$ Nur Ichwan, Meretas Kesarjanaan Kritis Al-Qur'an, 61.

${ }^{16}$ Nasr Hamid Abu Zaid, Kritik Wacana Agama, trans. Khoiron Nahdiyyin (Yogyakarta: LKIS, 2003), 86.

${ }^{17}$ Nur Ichwan, “Al-Qur'an Sebagai Teks,” 158-59. 
cara pandang terhadap al-Qur'an dari teks yang bersifat ilahi menjadi teks manusiawi setelah hadir dalam dunia empiris.

Dalam "konteks kebudayaan" inilah Abu Zayd mengatakan bahwa alQur'an dan hadis adalah teks linguistik, teks historis, dan teks manusiawi. Ketiga istilah tersebut terangkum dalam keberadaan al-Qur'an sebagai teks susastra. Oleh karena itu, pendekatan sastra tidak bisa meninggalkan aspek linguistik, historis, dan kemanusiawian teks, yang kesemuanya itu berangkat dari konteks budaya Arab abad ketujuh. ${ }^{18}$

Menurut Nasr, dalam makna bahasa terdapat dua dimensi yang terlihat kontradiktif, namun sebenarnya saling melengkapi. Istilah tersebut adalah tafsir dan takwil. Tafsir memiliki pengertian makna lahir dari sebuah teks. Sementara, takwil adalah unsur batin teks ${ }^{19}$ yang digunakan untuk mengungkapkan makna dan maghza. Makna adalah arti yang dibangun berdasarkan gramatikal teks, sehingga makna yang dihasilkan adalah makna-makna gramatik. Sedangkan, maghza menunjukkan pada makna dalam konteks sosio-historis. Dalam proses penafsiran, kedua hal ini saling berhubungan dengan kuat, maghaa selalu mengikuti makna begitu pula sebaliknya. ${ }^{20}$

Penafsiran al-Qur'an dan hadis sebagai teks tidak dapat hanya dipahami melalui analisis linguistik, tetapi juga konteks historis pada saat al-Qur'an dan hadis turun karena teks memiliki dimensi historis. Analisis terhadap teks menurut konteks saat itu perlu dilakukan karena pesan Islam tidak akan tersampaikan, jika masyarakat pendengar pertama tidak memahaminya. Jika teks dipahami oleh masyarakat dalam konteks yang berbeda, maka akan melahirkan pemahaman berbeda pula mengenai pesan yang terkandung dalam teks. Oleh karena itu, pemahaman generasi Muslim pertama terhadap pesan teks tidak dianggap sebagai pemahaman yang mutlak dan absolut. ${ }^{21}$

Jadi, ketika melakukan interpretasi, menurut Nasr Hamid, penafsir harus berangkat dari dua sudut pandang. Pertama, sudut sejarah untuk menempatkan teks-teks dalam konteks saat itu dalam rangka menyingkap makna aslinya. Kedua, sudut konteks sosiologis-budaya saat ini yang merupakan faktor pendorong untuk melakukan reinterpretasi terhadap teks. Hal ini dilakukan untuk membedakan antara makna asli dengan maghza atau signifikansi. ${ }^{22}$ Setelah

${ }^{18}$ Ibid., 160.

${ }^{19}$ Nasr Hamid Abu Zaid, Mafbum Al-Nash; Dirasah Fi Ulum Al-Qur'an (Kairo: AlHay'ah Al-Mishriyyah Al-Ammahli Al-Kitab, 1993), 252-62.

${ }^{20}$ Imron, "Hermeneutika Al-Qur'an Nasr Hamid Abu Zayd," 124.

${ }^{21}$ Ibid., 126.

${ }^{22}$ Abu Zaid, Kritik Wacana Agama, 120. 
mengetahui makna dan signifikansi, maskut anbu atau hal yang tak terkatakan adalah pesan lain yang harus diungkap dalam teks. ${ }^{23}$

Makna, signifikansi, dan maskut anbu adalah tiga konsep utama dalam hermeneutika Abu Zayd. Makna adalah apa yang dihadirkan oleh teks, sedangkan signifikansi apa yang muncul dalam hubungan antara makna dan pembaca. Makna besifat tetap, sedangkan signifikansi berubah. Sementara makut anhu merupakan pesan implisit yang tak terkatakan oleh teks.

Menurut Abu Zayd, ada tiga level makna pesan dalam teks-teks keagamaan. Level pertama adalah makna yang hanya merujuk kepada bukti atau fakta historis yang tidak dapat diinterpretasikan secara metaforis. Level kedua adalah makna yang menunjuk kepada bukti atau fakta historis dan dapat dinterpretasikan secara metaforis. Level ketiga adalah makna yang bisa diperluas berdasarkan atas signifikansi yang dapat diungkap dari konteks sosio-kultural dimana teks itu berada. ${ }^{24}$

Kemudian, Abu Zayd juga mengemukakan lima level konteks yang harus diperhatikan oleh penafsir. Pertama, konteks sosio-kultural yang terdiri dari aturan sosial dan kultural, dengan semua konvensi adat istiadat dan tradisi yang terekspresikan dalam bahasa teks itu. kedua, konteks eksternal, yakni konteks percakapan yang diekspresikan dalam struktur bahasa suatu teks. Ketiga, konteks internal yang berkaitan dengan "ketakintegralan" struktur teks dan pluralitas level wacananya. Struktur teks menurut Nasr tidak integral. Keempat, konteks linguistik yang tidak berkaitan dengan elemen-elemen suatu kalimat atau korelasi antar kalimat, atau berkaitan dengan perluasan figuratif dalam arti bentuk-bentuk gramatikal, namun juga berkaitan dengan signifikansi yang implisit di dalam struktur wacana. Kelima, konteks pembacaan yang pada hakikatnya adalah sebuah dekonstruksi kode. ${ }^{25}$

Menurut Nur Ichwan, metode yang ditawarkan oleh Abu Zayd adalah metode pembacaan kontekstual. Metode ini merupakan pengembangan dari ushul fiqih dan pendekatan sastra yang dirintis oleh Amin al-Khuli. Adapun langkah-langkah praktisnya dapat dirumuskan dalam lima langkah. Pertama, mengumpulkan ayat-ayat atau hadis-hadis yang setema, tetapi tetap menghargai kekhasan masing-masing ayat. Tahap ini banyak menggunakan analisis linguistik dan sastrawi. Kedua, menganalisis ayat-ayat atau hadis-hadis tersebut untuk dilihat level maknanya. Apakah perlu ditafsirkan secara metaforis atau tidak. Kritik historis digunakan pada tahap ini untuk melihat makna asli teks dan level makna. Ketiga, memperhatikan arah teks-teks yang dibaca. Untuk melihat arah ini

265.

${ }^{23}$ Nuryansah, “Aplikasi Hermeneutika Nashr Hāmid Abū Zaid Terhadap Hadis Nabi,”

${ }^{24}$ Nasr Hamid Abu Zaid, Naqd Al-Khittab al-Dini (Kairo: Sinar li al-Nasyr, 1992), 203.

${ }^{25}$ Nur Ichwan, Meretas Kesarjanaan Kritis Al-Qur'an, 90-93. 
diperlukan pengetahuan mengenai konteks penurunan ayat, mana yang diturunkan lebih dahulu dan belakangan. Ilmu Makkiyah, Madaniyyah, serta asbab al-nuzul dan wurud digunakan. Keempat, mencari aspek-aspek yang tersirat di dalam teks-teks tersebut. Di sini kritik historis dan analisis linguistik serta sastra dimainkan secara serentak dalam proses pembacaan. Kelima, melakukan kritik ideologi terhadap pembacaan sendiri. Sejauh mana kesubjektifan penafsir berpengaruh dalam penafsiran. Ideologi dan kecenderungan penafsir sebisa mungkin ditekan agar tidak merusak objektivitas interpretasi. ${ }^{26}$

\section{Aplikasi Hermeneutika Nasr Hamid terhadap Hadis-Hadis Keutamaan Menghafal al-Quran dalam Membaca Fenomena Hafiz Indonesia di RCTI}

Pada bagian ini akan dijelaskan terkait pengaplikasian hermeneutika Nasr Hamid terhadap hadis-hadis yang berbicara mengenai keutamaan menghafal alQur'an. Berdasarkan hermeneutikanya, ada tiga hal yang akan diungkap yakni dalalah (makna), maghza (signifikansi), dan maskut anbu (hal yang tak terkatakan). Ketiganya merupakan konsep vital dalam hermeneutika Nasr hamid.

\section{Hadis-hadis Nabi}

Hadis yang berbicara tentang keutamaan bagi penghafal al-Qur'an sangat banyak. Namun, yang disajikan di bawah ini dianggap sudah mewakili garis besar informasi terkait hal tersebut.

Hadis pertama,

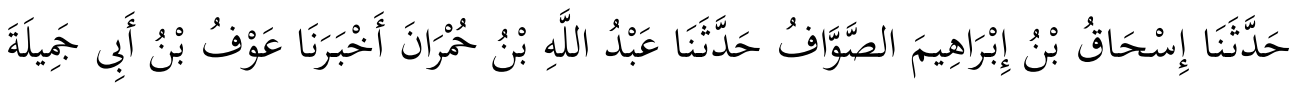

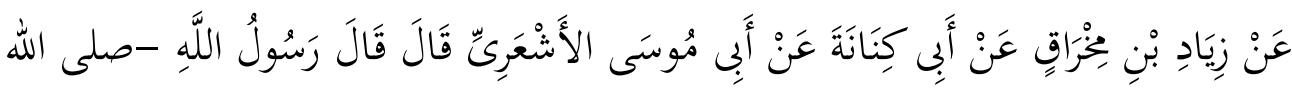

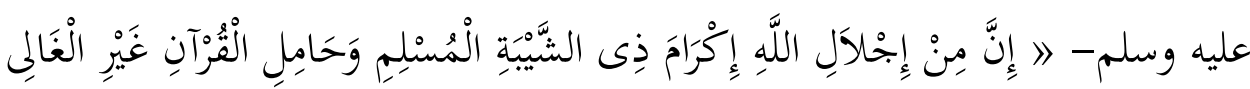

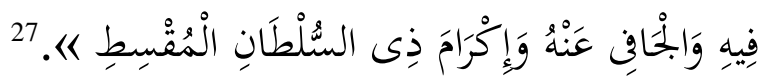

Telah menceritakan kepada kami Ishaq bin Ibrahim Ash Shawwaf berkata, telah menceritakan kepada kami Abdullah bin Humran berkata, telah mengabarkan kepada kami Auf bin Abu Jamilah dari Ziyad bin Mikbraq dari Abu Kinanah dari Abu Musa Al Asy'ari ia berkata, "Rasulullah shallallabu 'alaibi wasallam bersabda: "Termasuk dari

\footnotetext{
${ }^{26}$ Ibid., 104.

${ }^{27}$ Sulaiman al-Sijistani Abu Dawud, Sunan Abi Dawnd (Beirut: Dar al-Kutub Arabi, n.d.), j.4, 411.
} 
keagungan Allah adalah dimuliakannya seorang muslim yang telah beruban, para pembaca Al-Qur'an yang tidak bersikap belebihan di dalamnya dan tidak pula bersikap jauh darinya dan penguasa yang adil.

Dalam kitab Sunan Abu Dawud, hadis ini dihukumi hasan oleh alAlbani. ${ }^{28}$ Penilaian yang sama juga terdapat dalam beberapa kitab lainnya seperti Mirqat al-Mafatih Syarh Misykeat al-Mashabih ${ }^{29}$ dan kitab al-Adabu al-Mufradu bi al-Ta'liqat, bab al-Ijlal al-Kabir ${ }^{30}$. Meskipun kedua kitab tersebut bukan kitab matn hadis, namun hadis yang tertulis di dalamnya dilengkapi dengan statusnya. Lebih jauh Abu Umar menerangkan makna hadis tersebut secara gambling dalam kitabnya al-Tambid Lima fi al-Munvaththa min al-Ma'ani wa al-Asanid. ${ }^{3}$

Hadis kedua,

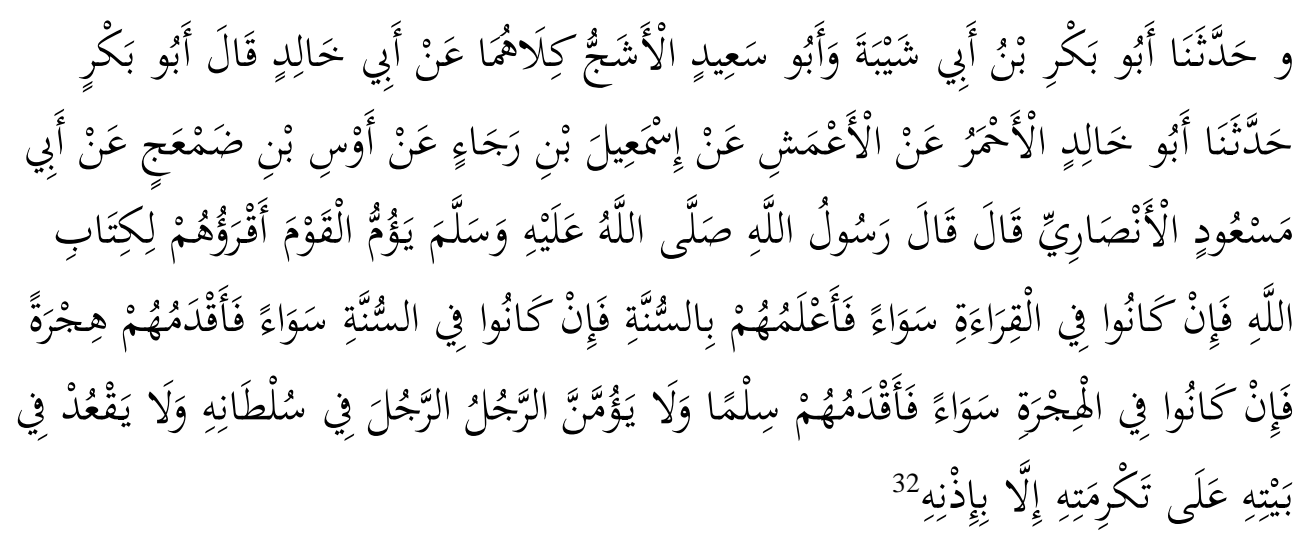

Dan telah menceritakan kepada kami Abu Bakr bin Abu Syaibab dan Abu Said Al Asyaj, keduanya dari Abu Khalid. Abu Bakr mengatakan; telah menceritakan kepada kami Abu Khalid Al Abmar dari Al A'masy, dari Ismail bin Raja' dari Aus bin Dham'aj dari Abu Mas'ud Al Asnhari, katanya; Rasulullah shallallabu 'alaibi wasalam bersabda: "Yang berbak menjadi imam atas suatu kaum adalah yang paling menguasai bacaan kitabullah (Alquran), jika dalam bacaan kapasitasnya sama, maka yang paling tabu terbadap sunnah, jika dalam as sunnah (hadis) kapasitasnya sama, maka yang paling dabulu bijrah, jika dalam bijrah sama, maka yang pertama-tama masuk. Islam, dan jangan

${ }^{28}$ Ibid., j. 4, 261.

${ }^{29}$ 'Aliy ibn Muhammad and Abu al-Hasan Nur al-Din al-Mala al-Harawi al-Qari, Mirqat Al-Mafatih Syarb Misykat al-Mashabih (Beirut: Dar Al-Fikr, 2002), j. 8, 3144.

${ }^{30}$ Muhammad ibn Isma'il ibn Ibrahim ibn al-Mugirah al-Bukhari, Shabih Al-Bukhari (Riyadh: Maktabah al-Ma'arif, 1997), j. 1, 185.

${ }^{31}$ Abu Umar Yusuf ibn 'Abdillah ibn Muhammad ibn'Abd al-Birr ibn 'Ashim al-Namri al-Qurthubi, Al-Tambid Lima Fi al-Munaththa Min al-Ma'ani Wa al-Asanid (Al-Maghrib: Wizarah 'Umum al-Auqaf wa al-Syu'un al-Islamiyyah, 1487), j. 17, 429.

${ }^{32}$ Muslim bin al-Hajjaj al-Naisaburi, Sahih Muslim (Beirut: Dar Ihya al-Turats Arabi, n.d.), j. 1, 465 . 
seseorang mengimami seseorang di daerah wewenangnya, dan jangan duduk di rumah seseorang di ruang tamunya, kecuali telah mendapatkan izin darinya".

Dalam Musnad Imam Abmad ibn Hanbal disebutkan bahwa sanad hadis tersebut berstatus shahih 'ala syarth muslim, yaitu Isma'il ibn Raja' Ibn Rabi'ah alZubaidi, Aus ibn Dam'aj dan perawilainnya dinilai tsiqah. Hadis ini juga diriwayatkan oleh Al-Thayalisi, Abu Dawud, Ya'qub ibn Sufyan dalam kitab alMa'rifah wa al-Tarikh, Ibnu Khuzaimah, Abu 'Awanah dan Ibnu Hibban. ${ }^{33}$ Penilaian yang sahih juga disebutkan al-Albani dalam Sunan Abi Dawud ${ }^{34}$ dan Sunan al-Turmidzi dengan bab yang sama "Man Ahaqqa bi al-Imamah".

Hadis ketiga,

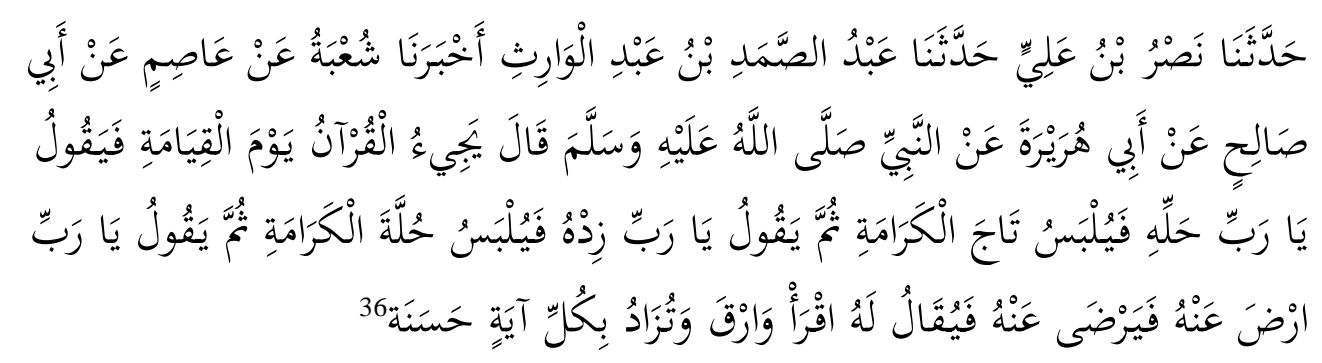

Telah menceritakan kepada kami Nashr bin Ali telab menceritakan kepada kami Abdushshamad bin Abdul Warits telah mengabarkan kepada kami Syu'bah dari 'Ashim dari Abu Shalih dari Abu Hurairah dari Nabi shallallahu 'alaibi wasallam beliau bersabda: "Pada hari kiyamat, Al Qur'an akan datang kemudian berkata; "Wahai Rabb berilah dia pakaian," maka dipakaikanlab kepadanya mabkota kemuliaan, kemudian Al Qur'an berkata lagi; "Wahai Rabb, tambabkanlab kepadanya, "Maka dipakaikan kepadanya pakaian kemuliaan, kemudian berkata lagi; "Wabai Rabb ridlailah dia, " akhirnya dia pun diridlai, kemudian dikatakan kepada abli Al Qur'an; "Bacalah dan naiklah, niscaya akan ditambabkean kepadamu satu pahala kebaikan pada setiap ayat.

Al-Tirmidzi menilai hadis ini sebagai hasan sahih. ${ }^{37}$ Imam Ahmad juga menambahkan dari jalur yang berbeda yaitu Ibnu Abi Sa'id al-Maqbari, dengan menyimpulkan bahwa sanadnya kuat. ${ }^{38}$

\footnotetext{
${ }^{33}$ Abu Abdillah Ahmad ibn Muhammad ibn Hanbal ibn Hilal ibn Asad al-Syaibani, Musnad Imam Ahmad Ibn Hanbal (Muassasah al-Risalah, 2001), j. 28, 295.

${ }^{34}$ Abu Dawud, Sunan Abi Dawnd, j. 1, 159.

${ }^{35}$ Abu Isa Muhammad bin Isa al-Tirmidzi, Sunan Al-Tirmidzi (Mesir: Syarikah Maktabah wa Mathba'ah Mushthafa al-Babiy al-Halabiy, 1975), j. 1, 458.

${ }^{36}$ Ibid., j. 5, 28.

${ }^{37}$ al-Syaibani, Musnad Imam Ahmad Ibn Hanbal, j. 16, 105.

${ }^{38}$ Ibid.
} 
Hadis keempat,

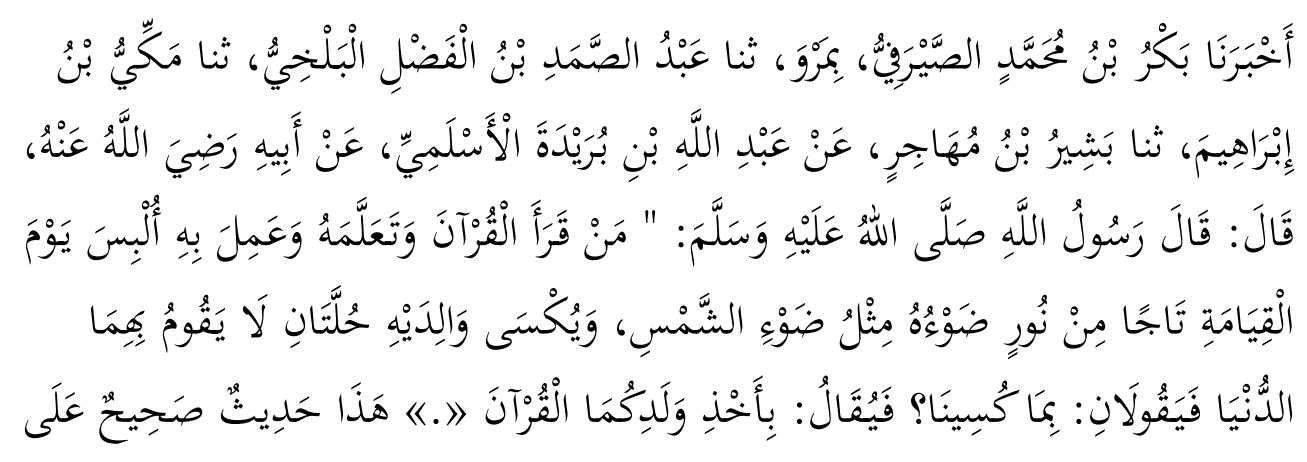

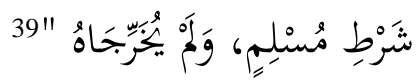

Dari Buraidah al-Aslami r.a, ia berkata bahwa ia mendengar Rasul bersabda, "Siapa yang membaca al-Qur'an, mempelajarinya, dan mengamalkannya, maka dipakaikan mabkota dari cahaya pada bari kiamat. Cahayanya seperti cahaya matabari. Kedua orang tuanya dipakaikan dua jubah (kemuliaan) yang tidak pernah didapatkan di dunia. Keduanya bertanya: mengapa kami dipakaikan jubah ini? Dijawab: "Karena kalian berdua memerintabkan anak. kalian untuk mempelajari al-Quran."

Hadis yang terakhir ini bisa dipastikan kualitasnya sahih karena menghimpun hadis-hadis yang terdapat dalam kitab sahih Bukhari dan Muslim.

\section{Konteks Historis Keutamaan Hadis-hadis Menghafal al-Qur'an}

Asbab al-wurud mikro dari hadis-hadis di atas tidak ditemukan secara rinci. Namun, melalui analisis makro, kita akan mengetahui alasan di balik kemunculan hadis-hadis tersebut. Al-Qur'an merupakan kitab suci umat Islam yang harus dijaga keakuratan baik huruf maupun bunyinya. Sementara, tradisi yang berkembang saat itu adalah hafalan. Oleh karena itu, untuk menjaga alQur'an agar tetap lestari adalah dengan cara menghafalnya.

Adapun alasan lainnya adalah secara kuantitas umat Islam belum mempunyai banyak pengikut. Terlebih, jumlah yang sedikit ini berada dalam tekanan dan ancaman yang dilakukan oleh masyarakat Quraisy. Terkadang pula, umat Islam harus menghadapi peperangan dengan kelompok yang menentangnya. Dengan adanya hal itu, banyak di antara para sahabat yang hafal al-Qur'an jatuh berguguran. Jika Nabi tidak mendorong para sahabat untuk menghafal al-Qur'an, maka keberadaan al-Qur'an sangat terancam.

${ }^{39}$ Abu Abdullah al-Hakim Muhammad bin Abdullah, Al-Mustadrak Ala al-Sabihain (Beirut: Dar al-Kitab al-Ilmiyyah, 1990), j. 1, 756. 


\section{Pemaknaan Hadis-hadis Keutamaan Menghafal al-Qur'an}

Hadis-hadis di atas menjelaskan keutamaan bagi penghafal al-Qur'an. Secara garis besar, hadis-hadis tersebut dapat diklasifikasikan menjadi tiga bagian. Pertama, keutamaan yang diperoleh hafidz di dunia. Hadis ini terdapat pada hadis pertama dan kedua. Pada hadis pertama dijelaskan bahwa menghormati orang yang menghafalkan al-Qur'an merupakan salah satu bentuk dalam mengagungkan Allah. Itu berarti, Rasul mengangkat derajat seorang hafidz dalam pergaulan dan hubungan sosialnya. Mereka ditempatkan pada posisi yang istimewa di masyarakat, sehingga mereka memiliki kedudukan mulia di tengah orang yang mengelilinginya.

Selain mendapat tempat dalam pergaulan sosial, seorang hafidz juga menjadi sosok terpandang terkait urusan ibadah. Hal tersebut terlihat seperti yang terangkum pada hadis kedua di atas. Hadis tersebut menyatakan bahwa seorang hafidz harus didahulukan untuk menjadi imam salat dibanding yang lainnya. Kehafidzan seseorang menjadi tolak ukur kelayakan menjadi pemimpin dalam ibadah khususnya salat. Dengan demikian, sangat jelas bahwa seorang hafidz memiliki kedudukan istimewa baik dalam sosial kemasyarakatan maupun ibadah.

Kedua, keutamaan yang didapat hafidz di akhirat. Keutamaan ini seperti yang disiratkan oleh hadis ketiga yang menyatakan bahwa kelak di akhirat, alQur'an akan menjadi saksi bagi seorang hafidz. Dengan perantara al-Qur'an, seorang hafidz juga akan mendapatkan mahkota kehormatan dan ridha Allah. Ini tentunya menjadi ungkapan yang menggiurkan karena al-Qur'an dapat menjadi jaminan bagi seseorang di akhirat untuk mendapatkan keselamatan yang berujung pada kenikmatan surga.

Ketiga, keutamaan yang disematkan pada orang tua hafidz di akhirat. Hal ini seperti yang diterangkan pada hadis keempat di atas. Hadis tersebut menjelaskan bahwa orang tua yang memerintahkan anaknya untuk mempelajari al-Qur'an -termasuk di dalamnya menghafal- akan mendapatkan jubah kehormatan atau kemuliaan kelak di akhirat. Dengan kata lain, anak yang paham al-Qur'an akan menjadi penyelamat bagi orang tuanya ketika hari pembalasan tiba. Implikasinya, mereka (satu keluarga) akan memperoleh kesenangan berupa surga dan terhindar dari neraka karena peran al-Qur'an.

Penjelasan di atas menggambarkan bahwa orang yang hafal al-Qur'an akan mendapat banyak keutamaan baik di dunia maupun akhirat. Selain keutamaan untuk diri sendiri, keutamaan lain juga berdampak pada orang tua mereka. Keutamaan-keutamaan tersebut mendorong orang Islam untuk menghafal al-Qur'an. Mereka berharap untuk memiliki keutamaan seperti yang dijelaskan dalam hadis tersebut. 
Untuk menemukan makna yang tepat, hadis-hadis tersebut harus dipahami terlebih dahulu sesuai konteks pada saat diproduksi. Nabi Muhammad saw merupakan nabi yang ummi yang banyak dipahami sebagai ketidakmampuan membaca dan menulis. Oleh karena itu, al-Qur'an yang diturunkan melalui malaikat Jibril diterima dengan cara hafalan. Ketika suatu ayat atau surah turun, beliau menghafalnya, kemudian mentransmisikannya kepada para sahabatnya. Para sahabat diperintah untuk menguasai dan menghafalnya. ${ }^{40}$

Pada saat itu, tradisi menulis belum mempunyai tempat yang signifikan. Sebaliknya, tradisi yang berkembang adalah hafalan atau lisan. Ini terindikasi dengan kemampuan mereka dalam menciptakan syair-syair atau puisi yang memiliki sastra tinggi. Mereka telah mencapai kesolidan tradisi ini dua atau tiga abad sebelum kedatangan Islam. ${ }^{41}$ Bangsa Arab, khususnya di Mekah dan Madinah terkenal dengan kekuatan hafalannya. Mereka terbiasa menghafal puisipuisi dan syair-syair Arab pra-Islam.

Biasanya, sebuah syair berakar dari kehidupan mereka yang membentuk pikiran dan menentukan karakter. Syair semata-mata hanya menjadi media ekspresi sastra. Setiap suku mempunyai syair yang dapat mewakili pikiran dan perasaannya. Bagi mereka, syair memberikan sebuah kehidupan ideal yang berdasarkan pada komunitas suku. Namun, syair dapat menjadi sebuah ikatan yang tak tampak antara suku-suku yang berbeda dan membentuk sebuah sentimen komunitas nasional. ${ }^{42}$

Islam dengan kitab sucinya yang baru lahir harus dijaga oleh para pemeluknya yang masih sedikit. Cara menjaga yang paling rasional dengan tradisi yang berkembang saat itu adalah menghafalnya. Poin penting pada konteks waktu itu adalah bagi menghafal lebih mudah daripada menulis. Walaupun ada bukti-bukti yang menunjukkan bahwa pada masa nabi sudah ada yang menulis potongan-potongan ayat. Media yang digunakannya adalah kulit dahan pohon palem, batu, kayu sadel unta, dan kulit binatang. ${ }^{43}$ Akan tetapi, tradisi tersebut tidak dimiliki oleh khalayak umum, melainkan hanya pada orang-orang tertentu.

Dengan demikian, dari analisis linguistik dan kritik historis dapat ditarik suatu kesimpulan bahwa dalalah (makna) dari hadis-hadis keutamaan menghafal al-Qur'an adalah suatu motivasi untuk menjaga al-Qur'an supaya tetap lestari 1994), 5-6.

${ }^{40}$ Ahsin W. Al-Hafidz, Bimbingan Praktis Menghafal Al-Qur'an Jakarta: Bumi Aksara,

${ }^{41}$ Tarif Khalidi, Arabic Historical Thought in the Classical Period (Cambridge Studies in Islamic Civilization) (Great Britain: Cambridge University Press, 1996), 1.

${ }^{42}$ Reynold A. Nicholson, A Literary History of The Arabs (Great Britain: Cambridge University Press, 1997), 72.

${ }^{43}$ Daniel Madigan, The Qur'an's Self Image: Writing and Authority in Islamic's Scripture (New Jersey: Princeton University Press, 2001), 14-15. 
dan tidak dilupakan. Hal ini sangat masuk akal karena secara kuantitas jumlah penganut Islam masih sangat terbatas. Itu masih ditambah dengan ancaman nyawa yang datang dari kelompok yang menolaknya. Umat Islam dalam posisi tertindas, sehingga semakin banyak sahabat yang hafal al-Qur'an akan semakin baik masa depan Islam.

Selain itu, menghafal sudah menjadi tradisi untuk menyampaikan ilmu pengetahuan saat itu. Pada intinya bagaimana cara agar al-Qur'an bisa tetap terjaga dan dapat diajarkan pada generasi selanjutnya. Cara yang dipilih Rasul adalah memotivasi dan mendorong para sahabat agar menghafalkan al-Qur'an dengan menunjukkan keutamaan-keutamaan yang akan diperoleh baik di dunia maupun akhirat. Keutamaan-keutamaan tersebut merupakan stimulus agar para sahabat lebih giat dan bergairah dalam menghafal al-Qur'an karena masa depan Islam ada di tangan mereka.

\section{Signifikansi atau maghza Hadis-hadis Keutamaan Menghafal al-Qur'an}

Pada bagian ini, teks tidak lagi dilihat dari kaca mata historis, melainkan era kini. Berbeda dengan makna teks yang bersifat statis dan mapan, signifikansi dapat berubah disesuaikan dengan konteks pembacaan. Oleh karena itu, ia bersifat dinamis. Kedinamisan ini menjadi ciri khas dari konsep signifikansi karena titik tolak penafsirannya adalah konteks si penafsir. ${ }^{44}$ Sangat mungkin suatu signifikansi berbeda antara masa sekarang dengan satu abad yang akan datang.

Jika masa nabi tradisi yang berkembang adalah lisan yang berbasis hafalan, maka sekarang tradisi telah bergeser menjadi tulisan yang bersanding dengan teknologi. Setelah pembuatan kertas ditemukan, tradisi tulis mulai dominan. Apalagi kini, teknologi percetakan sudah sangat canggih, hingga mampu memproduksi permintaan yang banyak dalam tempo singkat. Ditambah, sekarang suatu file atau dokumen, termasuk al-Qur'an, dapat didigitalisasi dan disimpan dalam bentuk data baik di komputer maupun internet.

Realita-realita tersebut menegasikan kekhawatiran yang muncul pada level makna yakni ketakutan jika al-Qur'an akan hilang karena tidak ada yang menghafalnya. Dengan bantuan teknologi rasanya sangat kecil kemungkinan alQur'an akan lenyap. Percetakan dan data digital akan mampu menyimpan dan mendokumentasikan al-Qur'an yang sama persis dari masa ke masa. Teknologi

265.

${ }^{44}$ Nuryansah, “Aplikasi Hermeneutika Nashr Hāmid Abū Zaid Terhadap Hadis Nabi,” 
dalam hal ini sudah mampu memainkan peran sebagai memori yang menjadi acuan utama masa nabi.

Oleh karena itu, pada era kontemporer, cara pandang terhadap hadishadis tersebut harus dirubah. Untuk menemukan sudut pandang baru, sejenak analisis teks diperlukan. Jika teks-teks hadis mengenai keutamaan menghafal alQur'an diperhatikan, maka ada satu konsep yang tersurat. Semua teks hadis yang dijabarkan di atas hanya menjelaskan hubungan penghafal dengan Allah yang akan memberikan reward. Ini mengindikasikan bahwa relasi yang terjadi adalah relasi individu (penghafal) dengan Allah yang dikenal sebagai hablu min Allah. Inilah yang disebut dengan istilah kesalehan individu.

Secara teologis, menghafal, membaca, dan mempelajari al-Qur'an diyakini mempunyai nilai ibadah. Oleh karena itu, aktifitas-aktifitas demikian dapat dikategorikan sebagai kasalehan individu yang langsung hubungannya dengan Allah. Jika aktifitas ini dilihat dari satu sisi yakni relasi individu-Allah, maka penghafal akan mendapat pahala yang akan membantunya meraih kenikmatan di akhirat. kesimpulannya, kunci mendapatkan kehormatan baik di dunia maupun akhirat adalah menghafal al-Qur'an.

Akan tetapi, jangan dilupakan bahwa manusia adalah makhluk sosial. Ia pasti berinteraksi dengan manusia lainnya sebagai bagian dari kehidupan. Hal ini dikenal dengan istilah bablu min al-nas. Boleh jadi orang saleh secara individu, tetapi tidak dalam pergaulan sosial, begitu pula sebaliknya. Jadi, untuk memperoleh kemuliaan di dunia dan akhirat kasalehan individu saja tidaklah cukup. Ada hal lain yang harus dipertimbangkan yakni kesalehan sosial. Jadi, individu yang mampu menggabungkan keduanya adalah yang pantas memperoleh kehormatan di dunia dan akhirat.

Dengan demikian, yang dimaksud dengan menghafal pada hadis-hadis tersebut memiliki signifikansi mengamalkan al-Qur'an. Dalam artian, ia mampu melaksanakan ajaran-ajaran yang terkandung di dalamnya. Al-Qur'an bukan hanya hadir di memorinya, tetapi juga dalam tingkah lakunya. Kesalehan individu dan sosial juga bagian dari ajaran al-Qur'an. Oleh karena itu, orang yang mampu mengejewantahkan ajaran-ajaran al-Qur'an, sesungguhnya mereka adalah orang-orang yang dimaksud hadis akan mendapatkan kemuliaan dan kehormatan.

\section{Maskut Anhu Hadis-hadis Keutamaan Menghafal al-Qur'an}


Maskut anbu menjadi sesuatu yang tersembunyi dalam sebuah teks. Setiap teks apalagi yang berbicara tentang sebuah wacana biasanya mempunyai pesan yang tertulis secara implisit. Ia tidak tertulis dalam teks, tetapi mampu menjadi ruh sebuah teks. Sebagai pembaca kontemporer, maskut anbu ini sangat relevan untuk diungkap. Pengungkapannya tergantung pada sudut pandang dalam pembacaan terhadap fenomena tertentu.

Fenomena yang ingin dibaca di sini adalah acara perlombaan Hafiz. Indonesia yang disiarkan secara rutin setiap Ramadhan oleh salah satu TV swasta. Menghafal al-Qur'an yang mempunyai dimensi teologis, diarahkan kepada sesuatu yang bersifat matrealistis. Jika diperhatikan, acara perlombaan menghafal al-Qur'an yang ditayangkan lebih menonjolkan sisi dramanya dibandingkan inti acara tersebut yakni hafalan al-Qur'an. Drama tersebut disuguhkan untuk menyedot animo masyarakat supaya mereka tertarik dan menonton. Hal ini akan berdampak pada naiknya rating acara TV tersebut. Jika ini berhasil, maka keuntungan dari berbagai sponsor dan iklan akan didapat oleh pihak TV selaku penyelenggara.

Berbeda dengan penyelenggara yang mendapatkan keuntungan ekonomi, para peserta di samping mendapatkan uang, mereka juga mendapatkan ketenaran. Mereka akan menjadi terkenal jika mampu berpartisipasi dalam acara tersebut, terlebih jika bisa menjadi juara. Hal-hal seperti ini akan mempengaruhi otak bawah sadar para peserta yang biasanya masih anak-anak. Motif atau tujuan mereka menghafal bisa bergeser dari yang tadinya semata-mata untuk mencari ridha Allah menjadi motif ekonomi dan popularitas. Menghafal al-Qur'an digunakan sebagai batu loncatan untuk meraih keduanya. Tentu saja, ini sangat bertolak belakang dengan tujuan awalnya.

Jadi, maskut anbu hadis-hadis keutamaan menghafal al-Qur'an adalah larangan menghafal al-Qur'an untuk kepentingan ekonomi dan popularitas. Tidak semestinya al-Qur'an yang bernilai sakral dijadikan media untuk mengeruk hal yang profan. Menghafal al-Qur'an sudah semestinya diniatkan hanya karena Allah, bukan hal lainnya apalagi untuk sesuatu yang bersifat keduniawian. Larangan ini dimaksudkan untuk mengembalikan tujuan awal menghafal alQuran yakni mendapat ridha Allah dengan cara mengamalkan ajaran-ajaran yang terkandung di dalamnya. 
74 | AL QUDS : Jurnal Studi Alquran dan Hadis vol. 4, no 1, 2020

\section{Kesimpulan}

Menurut hadis, orang-orang yang menghafalkan al-Qur'an akan mendapatkan banyak keutamaan baik di dunia maupun akhirat. Jika hadis-hadis tersebut didekati menggunakan hermeneutika Nasr Hamid, akan diperoleh dua level pemaknaan yakni dalalat (makna) dan maghza (signifikansi). Berdasarkan keterangan di atas, makna dari hadis-hadis tersebut adalah sebuah motivasi yang diberikan nabi kepada para sahabat agar menghafalkan al-Qur'an. Al-Qur'an harus dijaga melalui hafalan agar dapat diajarkan kepada generasi selanjutnya. Sementara, signifikansinya adalah mengamalkan ajaran-ajaran yang terkandung dalam al-Qur'an. Kesalehan individu dan sosial harus dijalankan agar memperoleh keutamaan-keutamaan yang dijanjikan dalam hadis. Adapun maskut anbunya adalah larangan menghafal al-Qur'an demi kepentingan ekonomi dan popularitas.

\section{Bibliografi}

A. Nicholson, Reynold. A Literary History of The Arabs. Great Britain: Cambridge University Press, 1997.

Abu Dawud, Sulaiman al-Sijistani. Sunan Abi Dawnd. Beirut: Dar al-Kutub Arabi, n.d.

Abu Zaid, Nasr Hamid. Kritik Wacana Agama. Translated by Khoiron Nahdiyyin. Yogyakarta: LKIS, 2003.

. Mafbum Al-Nash; Dirasah Fi Ulum Al-Qur'an. Kairo: Al-Hay'ah AlMishriyyah Al-Ammahli Al-Kitab, 1993.

. Naqd Al-Kbittab al-Dini. Kairo: Sinar li al-Nasyr, 1992.

Ahmad, Nur. "Kajian Hermeneutik Al-Qur'an Kontemporer: Telaah Kritis Terhadap Model Hermeneutika Nasr Hamid Abu Zaid." HERMENEUTIK 9, no. 1 (2015): 115-38. doi:10.1234/hermeneutik.v9i1.886.

Al-Hafidz, Ahsin W. Bimbingan Praktis Menghafal Al-Qur'an. Jakarta: Bumi Aksara, 1994.

Aliy ibn Muhammad, and Abu al-Hasan Nur al-Din al-Mala al-Harawi al-Qari. Mirqat Al-Mafatih Syarb Misykat al-Mashabih. Beirut: Dar Al-Fikr, 2002.

Bukhari, Muhammad ibn Isma'il ibn Ibrahim ibn al-Mugirah al-. Shabih AlBukhari. Riyadh: Maktabah al-Ma'arif, 1997.

"Hafiz Indonesia." In Wikipedia bahasa Indonesia, ensiklopedia bebas, February 20, 2020. 
https:/ /id.wikipedia.org/w/index.php?title=Hafiz_Indonesia\&oldid $=16$ 576004 .

Hamdani, Fikri. "Teori Interpretasi Nasr Hamid Abu Zayd." Farabi: Journal of Ushuluddin \& Islamic Thought 13, no. 1 (2016): 30-45.

Imron, Ali. "Hermeneutika Al-Qur'an Nasr Hamid Abu Zayd.” In Hermeneutika Al-Qur'an Dan Hadis, edited by Sahiron Syamsuddin. Yogyakarta: eLSAQ Press, 2010.

Khalidi, Tarif. Arabic Historical Thought in the Classical Period (Cambridge Studies in Islamic Civilization). Great Britain: Cambridge University Press, 1996.

Madigan, Daniel. The Qur'an's Self Image: Writing and Authority in Islamic's Scripture. New Jersey: Princeton University Press, 2001.

Muhammad bin Abdullah, Abu Abdullah al-Hakim. Al-Mustadrak Ala alSabihain. Beirut: Dar al-Kitab al-Ilmiyyah, 1990.

Naisaburi, Muslim bin al-Hajjaj al-. Sabih Muslim. Beirut: Dar Ihya al-Turats Arabi, n.d.

Nur Ichwan, Moch. "Al-Qur'an Sebagai Teks (Teori Teks Dalam Hermeneutik Qur'an Nasr Hamid Abu Zayd.” In Studi Al-Qur'an Kontemporer: Wacana Baru Berbagai Metodologi Tafsir, edited by Abdul Mustaqim and Sahiron Syamsuddin. Yogyakarta: Tiara Wacana, 2002.

. Meretas Kesarjanaan Kritis Al-Qur'an: Teori Hermeneutika Nasr Abu Zayd. Jakarta: Teraju, 2003.

Nuryansah, Mohamad. "Aplikasi Hermeneutika Nashr Hāmid Abū Zaid Terhadap Hadis Nabi (Studi Pada Hadis 'Perintah Memerangi Manusia Sampai mereka Mengucapkan tiada tuhan selain Allah')." Millati: Journal of Islamic Studies and Humanities 1, no. 2 (2016): 259-78. doi:10.18326/mlt.v1i2.259-278.

Qurthubi, Abu Umar Yusuf ibn 'Abdillah ibn Muhammad ibn'Abd al-Birr ibn 'Ashim al-Namri al-. Al-Tambid Lima Fi al-Munaththa Min al-Ma'ani Wa al- Asanid. Al-Maghrib: Wizarah 'Umum al-Auqaf wa al-Syu'un alIslamiyyah, 1487.

Rohmah, Lailatur. "Hermeneutika Al-Qur'an: Studi Atas Metode Penafsiran Nasr Hamid Abu Zaid." Hikmah Journal of Islamic Studies 12, no. 2 (2016): 223-44. 
76 | AL QUDS : Jurnal Studi Alquran dan Hadis vol. 4, no 1, 2020

Sa'adah, Fatkhiatus. "Pengaruh Intensitas Menonton Program Acara Hafiz Indonesia Di RCTI Terhadap Motivasi Membaca Al-Qur'an Remaja Di Desa Pasir Kecamatan Mijen Kabupaten Demak." Skripsi, Fakultas Dakwah dan Komunikasi UIN Walisongo Semarang, 2018.

Syaibani, Abu Abdillah Ahmad ibn Muhammad ibn Hanbal ibn Hilal ibn Asad al-. Musnad Imam Abmad Ibn Hanbal. Muassasah al-Risalah, 2001.

Tirmidzi, Abu Isa Muhammad bin Isa al-. Sunan Al-Tirmidqi. Mesir: Syarikah Maktabah wa Mathba'ah Mushthafa al-Babiy al-Halabiy, 1975. 